\title{
Early increase of TNF $\alpha$ and IL-6 in tracheobronchial aspirate fluid indicator of subsequent chronic lung disease in preterm infants
}

\author{
Baldvin Jónsson, Kjell Tullus, Annelie Brauner, Ying Lu, Gerd Noack
}

\begin{abstract}
Aim-To investigate if early changes in concentrations of proinflammatory cytokines in tracheobronchial aspirate fluid (TAF) from preterm infants could be used to detect infants at risk of chronic lung disease (CLD) and help in the selection of patients for early steroid treatment.

Methods-Twenty eight preterm infants less than 34 weeks of gestation (median 26 weeks) were intubated and daily measurements of TAF concentrations of tumour necrosis factor $\alpha$ (TNF $\alpha$ ) and the interleukins IL-1ß, IL-6, and IL-8 were made, using enzyme immunoassay techniques.

Results-Seventeen of the infants developed CLD. The infants who developed CLD had significantly increased concentrations of TNF $\alpha$, IL-1ß, IL-6 on days 2 and 3. TNF $\alpha$, IL-6, and IL-8 concentrations were significantly related to gestational age and duration of supplemental oxygen; TNFo, IL-6, and IL-8 concentrations also correlated with length of time on the ventilator.

Conclusion-These data indicate that tracheobronchial aspirate fluid cytokine concentrations may be used as a predictor of subsequent CLD and may help select a group of preterm infants at high risk of developing CLD for early treatment. (Arch Dis Child 1997;77:F198-F201)
\end{abstract}

Keywords: cytokines; chronic lung disease; tracheobronchial aspirate fluid; mechanical ventilation

Department of Paediatrics,

Karolinska Hospital, Stockholm, Sweden B Jónsson

K Tullus

Department of Anaesthesiology G Noack

Department of Microbiology

A Brauner

$\mathrm{Y} \mathrm{Lu}$

Correspondence to: Dr Baldvin Jonsson, Institution for Woman and Child Health, Division of Neonatology, Karolinska Hospital, 171-76, Stockholm, Sweden.

Accepted 6 May 1997 from preterm infants has been described. ${ }^{5-8}$ In a cross sectional study we found increased concentrations of proinflammatory cytokines in infants with CLD, and a decrease after treatment with corticosteroids. ${ }^{9}$

Our hypothesis is that the early appearance of cytokines in TAF can help to identify patients at high risk of developing CLD, and to select infants for early treatment with intravenous or inhaled corticosteroids. We therefore compared the antigen titres of the proinflammatory cytokines tumour necrosis factor $\alpha(\mathrm{TNF} \alpha)$ and the interluekins IL- $1 \beta$, IL-6, and IL-8 in TAF from intubated infants during the first weeks of life, who subsequently developed CLD, with those in a control group of infants with respiratory distress syndrome (RDS) that resolved without sequelae. We also studied the effect of gestational age, fraction of inspired oxygen $\left(\mathrm{FIO}_{2}\right)$ and insufflation pressure during mechanical ventilation on the proinflammatory cytokine values.

\section{Methods}

This study was conducted from January through December 1994 on mechanically ventilated infants, of 34 weeks gestation or less, admitted to the neonatal intensive care unit at the Karolinska Hospital in Stockholm, Sweden. Tracheobronchial fluid (TAF) was collected daily. A total of 32 patients were sampled. The median (range) gestational age for all infants was 26 (24-33) weeks and the birthweight was $871(530-2356) \mathrm{g}$. Infants with perinatal infections (two infants, one with Ureaplasma urealyticum and the other with group B Streptococcus), congenital malformations and/or syndromes $(n=2)$ were excluded from further analysis. Of the remaining 28 infants, 17 developed CLD and these were compared with the remaining 11 patients with uncomplicated RDS. Data on perinatal factors (mode of delivery, rupture of membranes, prenatal steroid treatment) were documented.

Respiratory distress syndrome was diagnosed in infants on the basis of characteristic radiographic findings, respiratory distress, and an increasing $\mathrm{FIO}_{2}$ requirement. ${ }^{10}$ Infants diagnosed with RDS and an $\mathrm{FIO}_{2}>0.6$ received rescue treatment with natural porcine surfactant $200 \mathrm{mg} / \mathrm{kg}$ (Curosurf, Serono, Italy), after intubation.

The infants were mechanically ventilated using a Sechrist 100B infant ventilator 
Table 1 Perinatal characteristics of RDS and CLD infants

\begin{tabular}{lccl}
\hline & RDS group $(n=11)$ & CLD group $(n=17)$ & Pvalue \\
\hline Birthweight (g) & $1039(595-2365)$ & $709(530-1766)$ & 0.0044 \\
Gestational age (weeks) & $27(26-33)$ & $25(24-30)$ & 0.0007 \\
Male & 4 & 9 & NS \\
Female & 7 & 8 & NS \\
Prenatal steroid & $7(64)$ & $11(65)$ & NS \\
PROM & $5(45)$ & $4(23)$ & NS \\
Delivery & 6 & 8 & \\
$\quad$ Caesarean & 5 & 9 & \\
\hline
\end{tabular}

Values are shown as number (\%); PROM denotes prolonged rupture of membranes.

Table 2 Ventilatory and clinical characteristics of study population

\begin{tabular}{llcl}
\hline & RDS group $(n=11)$ & CLD group $(n=17)$ & P value \\
\hline Max PIP (cm) & $23(20-26)$ & $24(22-28)$ & NS \\
Inspired oxygen $>21 \%$ (hours) & $80(48-672)$ & $1848(1008-5760)$ & 0.0001 \\
Ventilatory support (hours) & $72(48-120)$ & $624(120-1680)$ & 0.0001 \\
Surfactant & $8(73)$ & $15(88)$ & NS \\
PDA & $3(27)$ & $15(88)$ & $<0.001$ \\
Air leaks & $2(18)$ & $7(41)$ & 0.029 \\
\hline
\end{tabular}

Values are shown as median (range) or number (\%); PIP denotes peaked inspiratory pressure; PDA denotes patent ductus arteriosus.

(Sechrist Corp., Anaheim, California, USA) with initial ventilator settings of $\mathrm{FIO}_{2}>0.6$, a rate of 60 breaths per minute, a peak inspiratory pressure (PIP) of $<30 \mathrm{~cm} \mathrm{H}_{2} \mathrm{O}$, a positive end expiratory pressure (PEEP) of 3-4 $\mathrm{cm} \mathrm{H}_{2} \mathrm{O}$, and an inspiration:expiration ratio (I:E) of 1:2. If, despite conventional ventilation and surfactant administration, the infant had increasing $\mathrm{pCO}_{2}$, hypoxia and acidosis, high frequency oscillatory ventilation was started using the Sensor Medics 3100A oscillator (Sensor Medics Corp., CA).

Chronic lung disease (CLD) was diagnosed in infants who had been ventilated during the first week of life, had respiratory symptoms, an oxygen requirement and radiological findings at 28 days of age. Air leak was defined as the radiological presence of pulmonary interstitial emphysema and/or pneumothorax. Patent ductus arteriosus (PDA) was diagnosed from clinical signs and confirmed by echocardiography.

The study was approved by the local ethics committee of the Karolinska Hospital.

\section{SAMPLING PROCEDURE}

The collection of TAF samples was begun on day 2 of life and was repeated daily, in the same 8 hour period. TAF samples were only collected when endotracheal suctioning was clinically indicated. No additional procedures were needed. Parental consent was obtained for this modified nursing procedure. Before initiating the procedure $\mathrm{FIO}_{2}$ was adjusted to maintain saturation between $92-94 \%$ by pulse oximetry. In infants who received surfactant the first sample was taken at least 6 hours after administration.

With the infant supine $0.5 \mathrm{ml}$ of $0.9 \%$ sterile saline was instilled endotracheally via a 6.0 French catheter (Vygon, Ecouen, France) and a deep gentle endotracheal suctioning of lung and airway secretions was done by rotating the catheter and applying suction while withdrawing the catheter. To rinse aspirate from the catheter wall, the catheter was flushed with 0.5 $\mathrm{ml}$ of sterile saline. All remaining aspirated material was thus flushed into a sterile specimen trap. Tree to five manual breaths were given and the lavage procedure repeated. The total duration of each instillation was less than 40 seconds. The recovery of aspirated fluid ranged between $70-80 \%$ of the amount instilled. Samples from the two instillations were pooled. Samples were excluded from further analysis if blood was visible in the aspirate.

Samples were centrifuged at $1200 \mathrm{rpm}$ for 10 minutes. The supernatant fluid was frozen at $-70^{\circ} \mathrm{C}$ until subsequent assay.

CYTOKINE ANALYSIS

The supernatant fluids were used for cytokine determination by enzyme immunoassay (EIA). TNF $\alpha$, IL-1 $\beta$, IL- 6 and IL- 8 kits were obtained from R\&D systems (Abingdon, Oxon, UK). The limit of detection was defined as $0.5 \mathrm{pg} / \mathrm{ml}$ for $\mathrm{TNF} \alpha, 3.9 \mathrm{pg} / \mathrm{ml}$ for IL- $1 \beta, 3.13 \mathrm{pg} / \mathrm{ml}$ for IL-6 and $31.3 \mathrm{pg} / \mathrm{ml}$ for IL-8.

Cytokine concentrations are expressed as volume concentrations $(\mathrm{pg} / \mathrm{ml})$ as no other satisfactory correction factor is currently available. Albumin content, urea, or IgA secretory component have been used as correction units, but their use has been questioned because all are subject to individual variations depending on the disease state, sampling site, and fluid recovered. ${ }^{611-13}$

\section{STATISTICAL ANALYSIS}

Intra- and intergroup differences were first tested using analysis of variance. For comparison of clinical variables and differences in cytokine values between groups, the MannWhitney $U$ test was used. Differences in frequencies were tested using the $\chi^{2}$ test. Correlations of cytokine concentrations with clinical variables were tested using the Spearman rank correlation coefficient test. For the correlation analysis only the first sample from each patient was used $(n=28)$. A p value of less than 0.05 was considered significant.

\section{Results}

There were no differences in regard to sex, method of delivery, prolonged rupture of membranes (PROM) or prenatal steroid use between infants who subsequently developed CLD and those with uncomplicated RDS (table 1). The infants who developed CLD had significantly lower gestational ages and birthweights than infants with RDS (table 1). There were also significant differences between the groups in time spent on a ventilator and duration of supplemental oxygen (table 2). The infants who developed CLD had significantly more air leaks and PDA (table 2). We found no significant correlation between the time of diagnosis or closure of the PDA with concentrations of individual cytokines. No early deaths occurred in either group of infants. Two infants in the CLD group died at 6 months of age from CLD related complications.

By days $2(\mathrm{p}=0.0133)$ and $3(\mathrm{p}=0.026)$ neonates who developed CLD had significantly higher TNF $\alpha$ values than the RDS group of infants (fig 1A). In CLD infants and RDS control infants median (range) $\mathrm{TNF} \alpha$ values on day 2 were 6.5 (3-9) $\mathrm{pg} / \mathrm{ml}$ and $2.5(1-4)$ 
Figure 1 TAF fluid concentrations of proinflammatory cytokines in developed CLD and infants with uncomplicated RDS (shaded area). Bars indicate mean values with $95 \%$ confidence intervals, on separate days. (A) $\mathrm{TNFa}$ concentrations: *denotes $p<0.05$ on days 2 and 3 between CLD and RDS infants; ${ }^{+} p>0.05$ on days 6 and 7 compared with days 2 and 3 for CLD infants. (B) IL-1 $\beta$ antigen titres: ${ }^{\star} p<0.05$ between RDS and CLD infants on day 2. (C) IL 6 concentrations: ${ }^{\star} p<0.05$ on days 2 and 3 between the two groups of infants. (D) IL 8 concentrations infants who subsequently
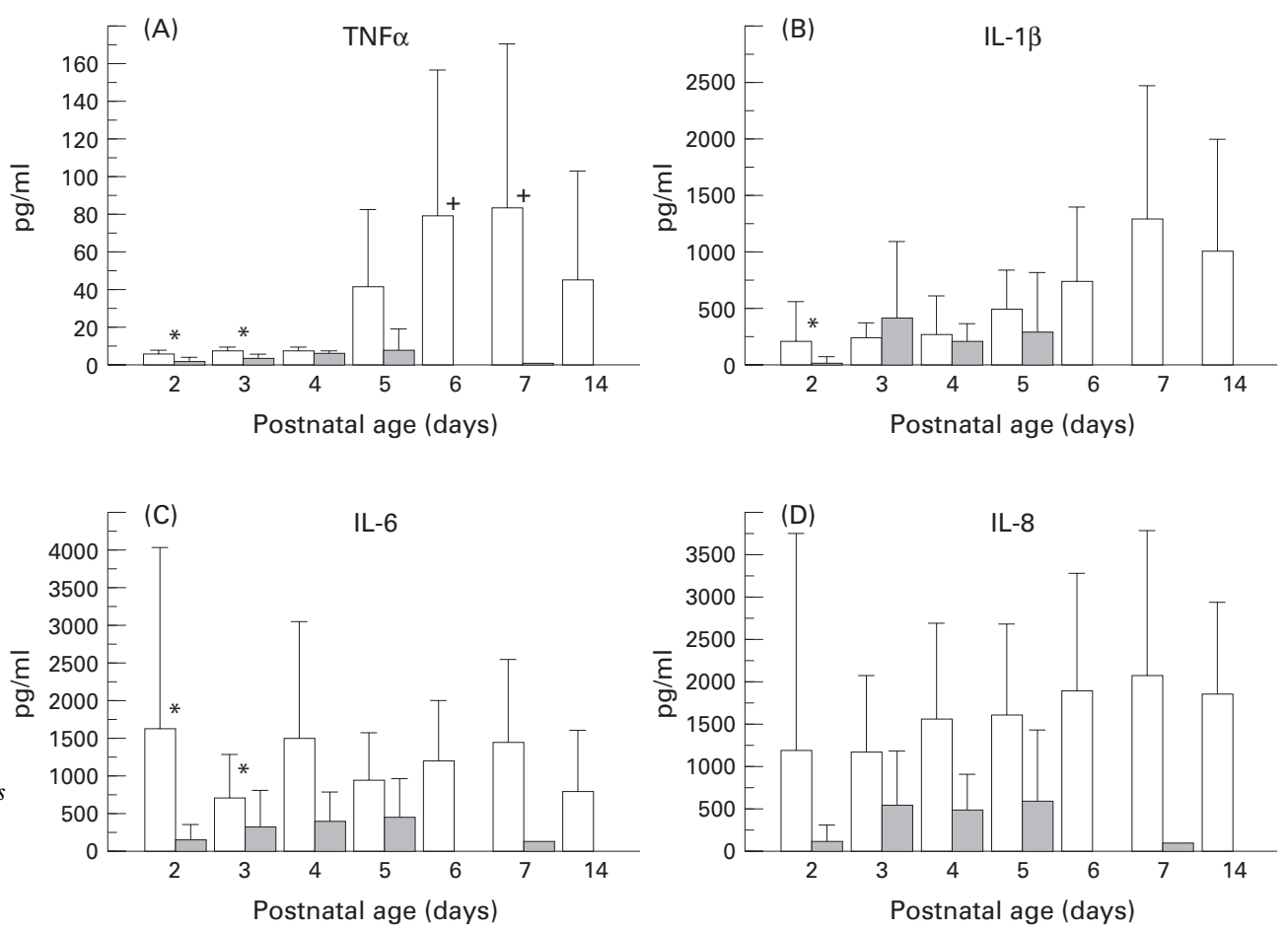

$\mathrm{pg} / \mathrm{ml}$, respectively. On day $2 \mathrm{TNF} \alpha$ concentrations of $\geqslant 5 \mathrm{pg} / \mathrm{ml}$ were found in six of seven samples in infants who subsequently developed CLD compared with none of the five control infants. In CLD infants TNF $\alpha$ values were significantly higher on days 6 and day 7 compared with day 3 ( $\mathrm{p}=0.044$ and 0.041 , respectively). $\mathrm{TNF} \alpha$ concentrations were significantly correlated with lower gestational age, birthweight, time spent on a ventilator and duration of supplemental oxygen (table 3 ).

IL-1 $\beta$ concentrations were significantly higher only in CLD infants on day 2 ( $\mathrm{p}=$ 0.046; fig 1B). IL-6 concentrations were significantly higher in CLD infants on days 2 $(\mathrm{p}=0.014)$ and day $3(\mathrm{p}=0.05)($ fig $1 \mathrm{C})$ compared with the RDS group. On day 2 median IL-6 concentrations were 1130 (390-3800) $\mathrm{pg} / \mathrm{ml}$ in CLD infants and $106(38-350) \mathrm{pg} / \mathrm{ml}$ in RDS infants. On day 2 IL- 6 concentrations over $350 \mathrm{pg} / \mathrm{ml}$ were found in all five samples in CLD infants but in none of the six control infant samples. IL- 6 concentrations correlated with lower gestational age, birthweight, time spent on a ventilator and duration of supplemental oxygen (table 3 ).

Overall, using an analysis of variance, IL-8 concentrations were significantly increased

Table 3 Correlation between cytokine concentrations and clinical variables (Spearman rank correlation showing $r_{s}(P$ value $)$ )

\begin{tabular}{|c|c|c|c|c|}
\hline & $T N F-a$ & $I L-1 \beta$ & $I L-6$ & $I L-8$ \\
\hline Gestational age & $-0.42(0.0002)$ & $-0.29(0.027)$ & $-0.41(0.003)$ & $-0.32(0.026)$ \\
\hline Birthweight & $-0.15(0.093)$ & $-0.05(0.70)$ & $-0.18(0.18)$ & $0.04(0.78)$ \\
\hline $\begin{array}{l}\text { Time with supplemental } \\
\text { oxygen }\end{array}$ & $0.29(0.018)$ & $0.07(0.61)$ & $0.36(0.01)$ & $0.18(0.12)$ \\
\hline $\begin{array}{l}\text { Duration of mechanical } \\
\text { ventilation }\end{array}$ & $0.36(0.024)$ & $0.12(0.37)$ & $0.42(0.003)$ & $0.21(0.10)$ \\
\hline $\begin{array}{l}\text { Maximal peak inspiratory } \\
\text { pressure } \\
\text { Time of appearance of air }\end{array}$ & $-0.01(0.92)$ & $-0.36(0.96)$ & $0.14(0.31)$ & $0.25(0.04)$ \\
\hline $\begin{array}{l}\text { Time of appearance of air } \\
\text { leak }\end{array}$ & $0.27(0.082)$ & $0.25(0.09)$ & $0.20(0.03)$ & $0.18(0.098)$ \\
\hline
\end{tabular}

from day 2 to day $7(\mathrm{p}=0.012)$ in CLD infants. There was no significant difference in values on separate days between the CLD and the RDS infants (fig 1D). IL-8 concentrations were significantly related to lower gestational age, duration of supplemental oxygen, time spent on a ventilator and maximal PIP (table 3 ).

\section{Discussion}

We have shown that proinflammatory cytokines are increased in TAF from as early as day 2 of life in mechanically ventilated preterm infants who subsequently developed CLD. Compared with the control RDS infants their concentrations of TNF $\alpha$, IL- $1 \beta$, and IL- 6 were significantly higher on days 2 or 3 of life. Our finding of increased cytokines early in the course of CLD supports the hypothesis that they are important mediators in the early inflammatory response in the preterm lung. On day 2 a cutoff limit of $350 \mathrm{pg} / \mathrm{ml}$ of IL-6 and $5 \mathrm{pg} / \mathrm{ml}$ of $\mathrm{TNF} \alpha$ in all cases selected only those infants who subsequently developed CLD. However, our study is to small to define such cutoff limits, but we suggest that further multicentre studies should aim at defining these break points, which could then indicate the potential for early treatment of evolving CLD.

The presence of a major ductal shunt is common in infants weighing less than $1000 \mathrm{~g}$ and is related to an increased incidence of CLD. ${ }^{14}$ PDA can increase pulmonary capillary pressure and promote the formation of oedema, and thus affect the concentrations of cytokines. We found that cytokine concentrations were higher in infants of lower gestational age and correlated with the duration of mechanical ventilation and oxygen exposure. This can reflect an exaggerated tissue response in the more immature lung, and the common presence of PDA and air leak are certainly important in this respect. Recent 
findings of decreased expression of the downregulatory cytokine IL-10 in mechanically ventilated preterm infants suggests that an imbalance between proinflammatory and downregulatory cytokines could be of great importance in the development of CLD. ${ }^{15}$

Increased concentrations of IL- $1 \beta$ or IL- 6 have been associated with chorioamnionitis and bacterial colonisation of the airways at birth in preterm infants. ${ }^{11}{ }^{16}{ }^{17}$ In mechanically ventilated preterm infants increased IL- 6 concentrations precede the influx of neutrophils into the airway. ${ }^{18}$ No previous study has reported the concentrations of all four proinflammatory cytokines at the same time (TNF $\alpha$, IL-1 $\beta$, IL- 6 , IL-8) during the first days of life. However, increased concentrations of individual cytokines, such as $\mathrm{TNF} \alpha,{ }^{19} \mathrm{IL}-1 \beta,{ }^{20}$ IL- $6^{6}$ and IL- $8^{8}$ have been described in lung secretions of infants who develop CLD.

In this study high IL-8 concentrations were found in the infants who developed CLD compared with the control infants with RDS. In infants with resolving RDS IL-8 concentrations decrease while the infants who develop CLD seem to have a sustained secretion of IL-8 with a continued influx of inflammatory cells into the lung. These cells release toxic products such as elastase which has been implicated in the development of CLD. ${ }^{21} 22$

Different surfactant preparations down regulate the release of pulmonary cytokines $\left(\mathrm{TNF} \alpha\right.$, IL-1 $\beta$, IL-6). ${ }^{23}$ Natural porcine surfactant decreases the release of $\mathrm{TNF} \alpha$ from human monocytes. ${ }^{24}$ In our study most infants received natural porcine surfactant as rescue treatment for RDS. The first samples were collected at least six hours after surfactant administration. It was not possible to evaluate the down regulatory effect of surfactant in this study as almost all infants received surfactant, but surfactant administration seems to have been insufficient to halt the significant increase in cytokine release.

Corticosteroids are thought to down regulate the release of inflammatory mediators. They are commonly used in the management of infants with developing or established CLD, often after the first week of life..$^{25}$ The effect of intravenous or inhaled steroids on tracheal aspirate concentrations of inflammatory markers in CLD has been documented. ${ }^{79}{ }^{26}$ As far as we are aware, no study has examined the effect of steroids administered during the first days of life on proinflammatory cytokine levels, in infants at risk of developing CLD.

In conclusion, we have demonstrated increased concentrations of proinflammatory cytokines in TAF from infants during the first days of life. The values correlate with gestational age and iatrogenic trauma in the form of oxygen exposure and mechanical ventilation. Increased concentrations of proinflammatory cytokines can therefore be the most valuable early indicator of developing CLD and will assist in selecting infants for interventions such as corticosteroid treatment or more selective blockage of components of inflammation.
This study was supported by the Swedish Heart Lung Foundation, Sällskapet Barnavård and the Swedish Medical Research Council (Grant B95-16X-08302-08A).

1 Northway W. An introduction to bronchopulmonary dysplasia. Clin Perinatol 1992;19:489-95.

2 deLemos R, Coalson J. The contribution of experimental models to our understanding of the pathogenesis and treatment of bronchopulmonary dysplasia. Clin Perinatol 1992;19:521-39.

3 Arnon S, Grigg J, Silverman M. Pulmonary inflammatory cells in ventilated preterm infants: Effect of surfactant treatment. Arch Dis Child 1993;69:44-8.

4 Kelley J. Cytokines of the lung. Am Rev Respir Dis 1990;141:765-88

5 Groneck P, Speer C. Inflammatory mediators and bronchopulmonary dysplasia. Arch Dis Child 1995;73:F1-F3.

6 Bagchi A, Viscardi R, Taciak V, Ensor J, McCrea K, Hasday $\mathrm{J}$. Increased activity of Interleukin- 6 but not tumor necrosis factor-a in lung lavage of premature infants is associated with the development of bronchopulmonary dysplasia. Pediatr Res 1994;36:244-52.

7 Groneck P, Speer C. Interleukin-8 in pulmonary effluent fluid of preterm infants. F Pediatr 1993;123:839-40.

$8 \mathrm{McColm} \mathrm{J}$, McIntosh N. Interleukin-8 in bronchoalveolar lavage samples as predictor of chronic lung disease in premature infants. Lancet 1993;343:729.

9 Tullus K, Noack G, Burman L, Nilsson R, Wretlind B, Brauner A. Elevated cytokine levels in tracheobronchial aspirate fluids from ventilator treated neonates with bronchopulmonary dysplasia. Eur f Pediatr 1996;155:112-16.

10 Hjalmarsson O. Epidemiology and classification af acute neonatal respiratory disorders. Acta Paediatr Scand 1981;70:773-83.

11 Watterberg K, Demers L, Scott S, Murphy S. Chorioamnionitis and early lung inflammation in infants in whom bronchopulmonary dysplasia develops. Pediatrics 1996;97:210-15.

12 Groneck P, Götze-Speer B, Oppermann M, Eiffert H, Speer C. Association of pulmonary inflammation and increased microvascular permeability during the development of bronchopulmonary dysplasia: a sequential analysis of inflammatory mediators in respiratory fluids of high-risk preterm neonates. Pediatrics 1994;93:712-18.

13 Watts C, Fanaroff A, Bruce M. Elevation of fibronectin levels in lung secretions of infants with respiratory distress syndrome and development of bronchopulmonary dysplasia. F Pediatr 1992;120:614-20.

14 Gonzalez A, Sosenko IRS, Chandar J, Hummler H, Cleure $\mathrm{N}$, Bancalari E. Influence of infection on patent ductus arteriosus and chronic lung disease in premature infants weighing 1000 grams or less. F Pediatr 1996;128:470-8.

15 Jones C, Cayabyab R, Kwong K, et al. Undetectable interleukin (IL)-10 and persistent IL-8 expression in early hyaline membrane disease: a possible developmental basis for the predisposition to chronic lung inflammation in preterm newborns. Pediatr Res 1996;39:966-75.

16 Groneck P, Goetze-Speer B, Speer C. Inflammatory bronchopulmonary response of preterm infants with microbial colonization of the airways at birth. Arch Dis Child 1996;74:F51-5.

17 Grigg J, Barber A, Silverman M. Increased levels of bronchoalveolar lavage fluid interleukin-6 in preterm infants ventilated after prolonged rupture of membranes. Am Rev Respir Dis 1992;145:782-6.

18 Munshi U, Niu J, Siddiq M, Parton L. Tracheal aspirate Interleukin-8 elevation followed by Interleukin-6 precede the appearance of neutrophils in preterm neonates who develop bronchopulmonary dysplasia. Pediatr Res 1996;39 (part 2):232A.

19 Murch S, MacDonald T, Wood C, Costeloe K. Tumor necrosis factor in the bronchoalveolar secretions of infants with the respiratory distress syndrome and the effect of with the respiratory distress syndrome and the
dexamethasone treatment. Thorax 1992;47:44-7.

20 Rozycki $H$ Bronchoalveolar Interleukin- 13 in infants on day 1 of life. South Med F 1994;87:991-6.

21 Merritt T. Oxygen exposure in the newborn guinea pig lung lavage cell populations. Chemotactic and elastase response: a possible relationship to neonatal bronchopulmonary dysplasia. Pediatr Res 1982;16:798-805.

22 Merritt T, Cochrane C, Holcomb K, et al. Elastase and a1proteinase inhibitor activity in tracheal aspirates during respiratory distress syndrome. F Clin Invest 1983;72:65666.

23 Sherman M, Laurie A, Campbell T. Effect of different surfactants on pulmonary group B streptococcal infection in premature rabbits. $\mathcal{F}$ Pediatr 1994;125:939-47.

24 Speer C, Götze B, Curstedt T, Robertsson B. Phagocytic functions and tumor necrosis factor secretion of human monocytes exposed to natural porcine surfactant (Curosurf). Pediatr Res 1991;30:69-74.

25 Ehrenkranz R, Mercurio M. Bronchopulmonary dysplasia. In: Sinclair J, Bracken $\mathrm{M}$, eds. Effective Care of the Newborn

26 Silverman M Chronic lung disease of prematurity: are we to cautious with steroids? Eur F Pediatr 1994;153:S30-5. 